\title{
The Influence of Carbon Fiber Heating Wire Spacing on Concrete Pavement Temperature
}

\author{
Yong $L A I^{1,2, a,{ }^{*}, \text { Yan LIU }}{ }^{1,2, b}$, Dao-Xun MA ${ }^{1,2, c}$, Xin SU ${ }^{1,2, d}$ \\ ${ }^{1}$ China Airport Construction Group Corporation, Beijing, 100101, China \\ ${ }^{2}$ Beijing Super-Creative Technology Co., LTD, Beijing, 100621, China \\ accacclaiyong@126.com, btjdoc@tom.com, daoxunma@126.com, dinsure@vip.sina.com \\ ${ }^{\star}$ Corresponding author
}

Keywords: Carbon Fiber Heating Wire, Pavement Temperature, Spacing, Heating Rate, Three-dimensional Infrared Ray Temperature.

\begin{abstract}
In this paper, the method of melting snow with carbon fiber heating wire (CFHW) buried in concrete pavement is presented to avoid the adverse effects of snow-melting chemicals. The pavement temperature, heating rate and temperature difference are analyzed. It is shown that, with an input power of $500 \mathrm{~W} / \mathrm{m}^{2}$, the average temperature on pavement surface with $10 \mathrm{~cm}$ CFHW spacing is higher than that of $15 \mathrm{~cm}$ CFHW spacing when the air temperature is $-5^{\circ} \mathrm{C}$ and the wind speed is $1.0 \mathrm{~m} / \mathrm{s}$. The temperature different on pavement surface with $10 \mathrm{~cm}$ CFHW spacing can meet the requirement of the snow-melting temperature uniformity.
\end{abstract}

\section{Introduction}

Snow, ice and slush on concrete pavement significantly impact aircraft landing and vehicle running in winter because snow, ice and slush reduce the friction coefficient between the tire and the pavement surface. The traditional method of pavement snow removal with snow-melting chemicals or machine induces traffic delay and needs a large number of manpower, chemicals and machine, which is labor intensive and time-consuming.

It is necessary to conduct timely and high-efficient removal of snow and avoid the adverse effects of snow-melting chemicals on concrete pavement. Some other pavement snow-melting methods have been researched, such as hydronic heating system ${ }^{[1-4]}$, electrically conductive concrete ${ }^{[5-7]}$ and $\mathrm{CFHW}^{[8-11]}$.

The current research of melting snow mainly focuses on CFHW. Zhao et al. conducted a systematic study on bridge deck and pavement snow-melting by embedding CFHW in concrete ${ }^{[9,10]}$. In different climatic conditions, the results showed that the method can meet the requirement of bridge deck and pavement snow-melting with different input powers. The CFHW spacing is an important factor of snow-melting project. However, the snow-melting method with CFHW requires further study on the application of pavement. Therefore, the influence of CFHW spacing on concrete pavement temperature is studied.

\section{Experiment}

\section{Materials}

The raw materials include cement, fine aggregate, coarse aggregate, water and CFHW. The mix proportions of concrete are given in Table 1. The cement is Ordinary Portland Cement 42.5. The fine aggregate is natural sand with fineness modulus of 2.85. The coarse aggregate gradation is the gravel 
of $5 \sim 40 \mathrm{~mm}$. The mixed water is tap water. The solid content of water reducer is $6.0 \%$. The ratio of water to cement is 0.42 . The heating material is $24 \mathrm{k} C F H W$, the resistance of which is $18.5 \Omega / \mathrm{m}$.

Tab.1 Mix Proportions of Concrete

\begin{tabular}{|c|c|c|c|c|c|}
\hline \multirow{2}{*}{$\begin{array}{l}\text { Cement } \\
\left(\mathrm{kg} / \mathrm{m}^{3}\right)\end{array}$} & \multirow{2}{*}{$\begin{array}{c}\text { Fine } \\
\text { aggregate } \\
\left(\mathrm{kg} / \mathrm{m}^{3}\right)\end{array}$} & \multicolumn{2}{|c|}{ Coarse aggregate $\left(\mathrm{kg} / \mathrm{m}^{3}\right)$} & \multirow{2}{*}{$\begin{array}{c}\text { Water } \\
\left(\mathrm{kg} / \mathrm{m}^{3}\right)\end{array}$} & \multirow{2}{*}{$\begin{array}{l}\text { Water reducer } \\
\qquad\left(\mathrm{kg} / \mathrm{m}^{3}\right)\end{array}$} \\
\hline & & $5-20 \mathrm{~mm}$ & $20-40 \mathrm{~mm}$ & & \\
\hline 325 & 579.9 & 567.9 & 851.8 & 136.5 & 6.5 \\
\hline
\end{tabular}

\section{Experiment Program}

The mixture is stirred for 90s according to GB/T 20473-2009. The specimens are prepared in the mould of $60 \mathrm{~cm} \times 60 \mathrm{~cm} \times 30 \mathrm{~cm}$. The $24 \mathrm{k}$ CFHW is located $5 \mathrm{~cm}$ below the pavement surface, which is bundled in steel mesh like snake. As shown in Fig.1(a), the A1 temperature sensor that is in the pavement surface is directly above the CFHW, and the CFHW spacing is $10 \mathrm{~cm}$; the $\mathrm{B} 1$ temperature sensor is in the center of pavement surface. As shown in Fig.1(b), the A2 temperature sensor that is in the pavement surface is directly above the CFHW, and the CFHW spacing is $15 \mathrm{~cm}$; the B2 temperature sensor is in the center of pavement surface. The cement concrete pavement is cured for 28 days at $20^{\circ} \mathrm{C}$ and $60 \% \pm 5 \%$ relative humidity. The $5 \mathrm{~cm}$ polystyrene insulation board is pasted at the bottom of and around pavement. The test carried out in the freezer that can be used to simulate outdoor weather in winter.

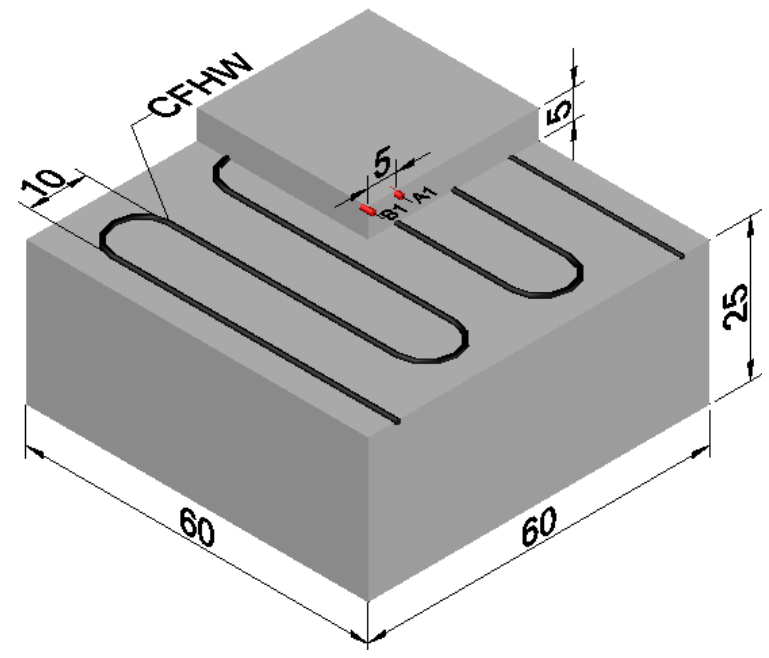

(a) $\quad 10 \mathrm{~cm}$ CFHW Spacing

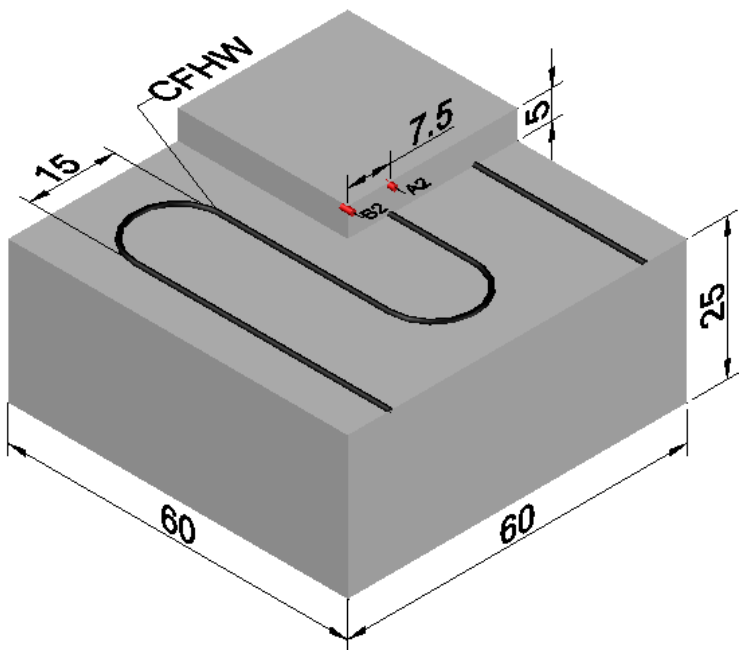

(b) $\quad 15 \mathrm{~cm}$ CFHW Spacing

Fig.1 Concrete Pavement Model

\section{Results and Discussion}

In the experiment, the input power was controlled by an $\mathrm{AC}$ booster. The heat flux of concrete pavement was $500 \mathrm{~W} / \mathrm{m}^{2}$. The average air temperature was $-5^{\circ} \mathrm{C}$; the wind speed was $1.0 \mathrm{~m} / \mathrm{s}$; the relative humidity was $90 \%$; the solar radiation intensity was $0 \mathrm{~W} / \mathrm{m}^{2}$. The pavements were placed to constant temperature in the freezer.

\section{Pavement Temperature and Heating Rate}

The concrete pavement surface temperature is measured against time as shown in Fig.2. The pavement heating experiment is stopped after 90 minutes heating, and then the pavement temperature data are collected to $180 \mathrm{~min}$. All pavement surface temperature curves are very smooth because of no radiation and stable convection. In the process of heating, the A1 and B1 point surface temperatures are in the range of $\mathrm{A} 2$ and $\mathrm{B} 2$ point surface temperatures. The $\mathrm{A} 1$ and $\mathrm{B} 1$ point temperatures rise above $0^{\circ} \mathrm{C}$ in 50 minutes; the $\mathrm{A} 2$ and $\mathrm{B} 2$ point temperatures rise above $0^{\circ} \mathrm{C}$ in 60 minutes. It is found 
that the pavement surface temperature of CFHW spacing of $10 \mathrm{~cm}$ is in the range of that of $15 \mathrm{~cm}$ for the same heat flux. The B1 and B2 point temperatures still rise within a short time when the electric power is turned off. The pavement surface temperature of $10 \mathrm{~cm}$ and $15 \mathrm{~cm}$ CFHW spacing begin to become consistent after stopping heating. The pavement surface temperatures decrease to $0^{\circ} \mathrm{C}$ at 180 minutes. The pavement heating rate variation with time is shown in Fig.3. The pavement heating rates of $10 \mathrm{~cm}$ and $15 \mathrm{~cm}$ CFHW spacing are almost the same except that the time is $0 \sim 20$ and 90 120 minutes. The pavement heating rate decreases steadily during 20 90 minutes. The pavement heating rate increases slowly during 120 180 minutes.

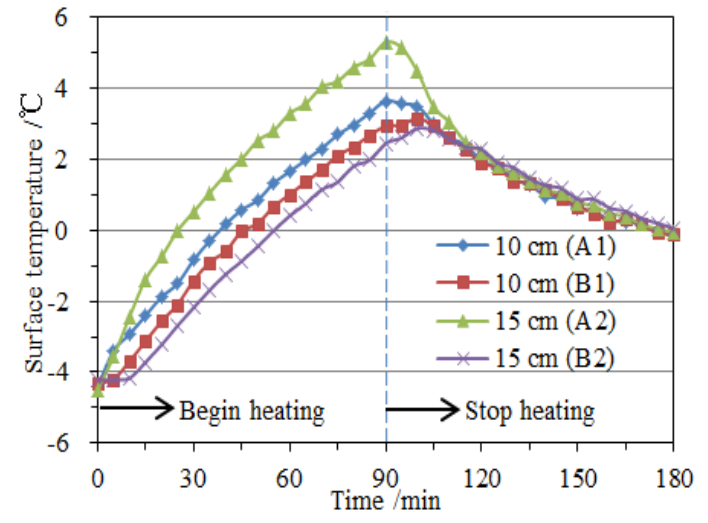

Fig.2 Pavement Surface Temperture Variation with Time

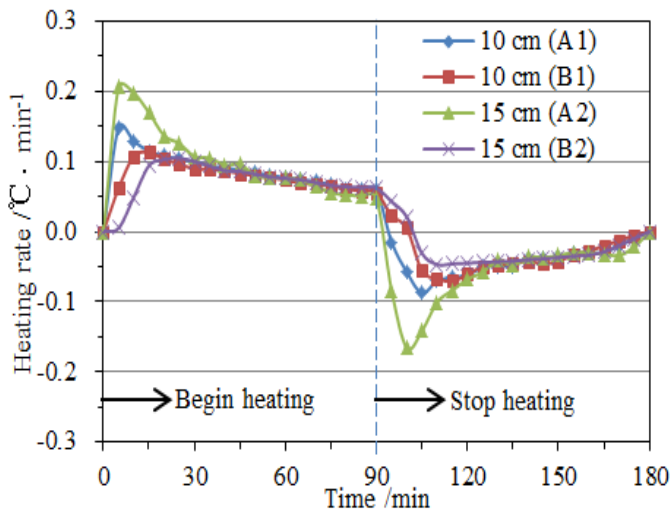

Fig.3 Heating Rate Variation with Time

The average temperature distributions along the depth of pavement at the initial time, power-off moment and 3h are shown in Fig.4. The average temperature is the average value of the same depth of pavement. At the same depth of pavement, the average temperature of CFHW spacing of $10 \mathrm{~cm}$ and is almost equal to that of $15 \mathrm{~cm}$ at the initial time and $3 \mathrm{~h}$. For the pavement surface, the average temperature of CFHW spacing of $10 \mathrm{~cm}$ is slightly higher than that of $15 \mathrm{~cm}$ at $1.5 \mathrm{~h}$. The average temperature of CFHW spacing of $10 \mathrm{~cm}$ is the same as that of $15 \mathrm{~cm}$ when the depth of pavement is more than $0.1 \mathrm{~m}$.

\section{Pavement Temperature Difference}

It can be seen from Fig. 5 that the maximum temperature difference on pavement surface is $0.8^{\circ} \mathrm{C}$ and $2.9^{\circ} \mathrm{C}$ for the CFHW spacing of $10 \mathrm{~cm}$ and $15 \mathrm{~cm}$, respectively. At the heating stage, the surface temperature difference curves of pavement with CFHW spacing of $10 \mathrm{~cm}$ and $15 \mathrm{~cm}$ increase to stable in $5 \mathrm{~min}$ and $20 \mathrm{~min}$, respectively. The surface temperature difference of pavement with CFHW spacing of $10 \mathrm{~cm}$ and $15 \mathrm{~cm}$ quickly reduce to $0^{\circ} \mathrm{C}$ after power-off, which indicates that the pavement surface temperature becomes consistent.

The three-dimensional infrared ray (3D-IR) temperature is obtained from the surface of concrete pavement. Fig.6 shows the 3D-IR temperature of pavement with CFHW spacing of $10 \mathrm{~cm}$ and $15 \mathrm{~cm}$ at initial time. The 3D-IR temperature of pavement with $10 \mathrm{~cm}$ CFHW spacing is from $-6.8^{\circ} \mathrm{C}$ to $-5.8^{\circ} \mathrm{C}$ at initial time, and the average temperature is $-6.2^{\circ} \mathrm{C}$. The $3 \mathrm{D}$-IR temperature of pavement with $15 \mathrm{~cm}$ $\mathrm{CFHW}$ spacing is from $-6.5^{\circ} \mathrm{C}$ to $-5.6^{\circ} \mathrm{C}$ at initial time, and the average temperature is $-6.1^{\circ} \mathrm{C}$. Fig.7 shows the 3D-IR temperature of pavement for $1 \mathrm{~h}$ heating. The 3D-IR temperature difference of pavement with CFHW spacing of $10 \mathrm{~cm}$ and $15 \mathrm{~cm}$ is $1.0^{\circ} \mathrm{C}$ and $3.1^{\circ} \mathrm{C}$, respectively. Their average temperature is $-0.4^{\circ} \mathrm{C}$ and $-0.6^{\circ} \mathrm{C}$. The maximum 3D-IR temperature difference is large relatively because of the uneven pavement surface and the different distance between the pavement and the infrared thermal imager. 


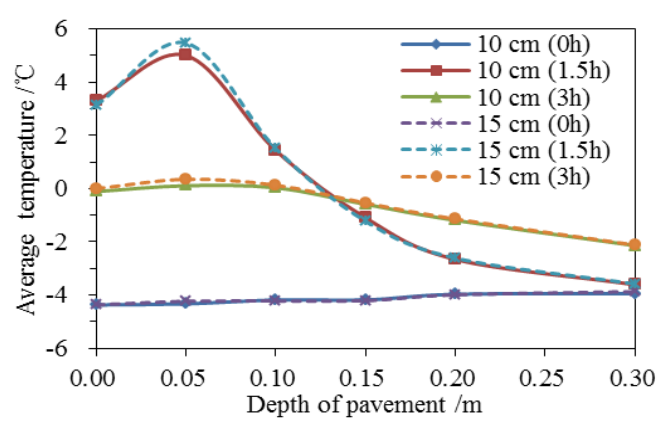

Fig.4 Average Temperture along the Depth of Pavement

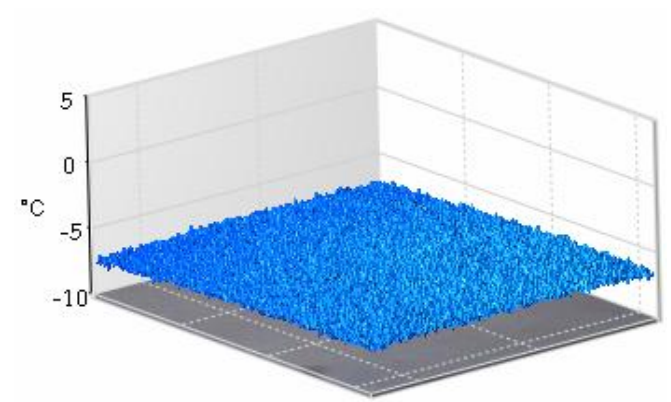

(a) $10 \mathrm{~cm}$

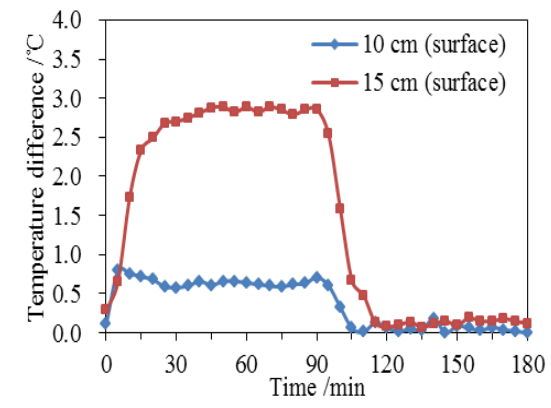

Fig.5 Pavement Surface Temperture Difference

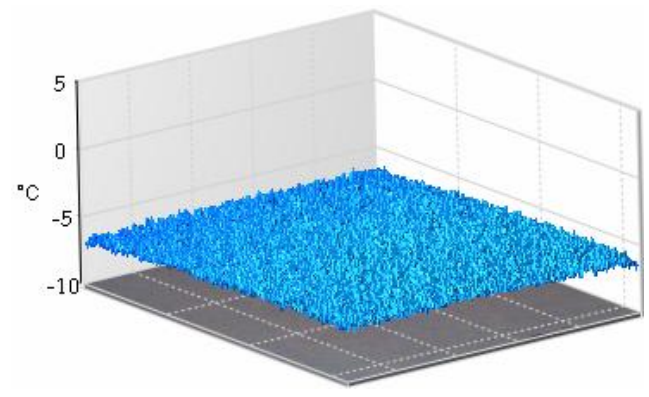

(b) $15 \mathrm{~cm}$

Fig.6 3D-IR Temperture of Pavement at Initial Time

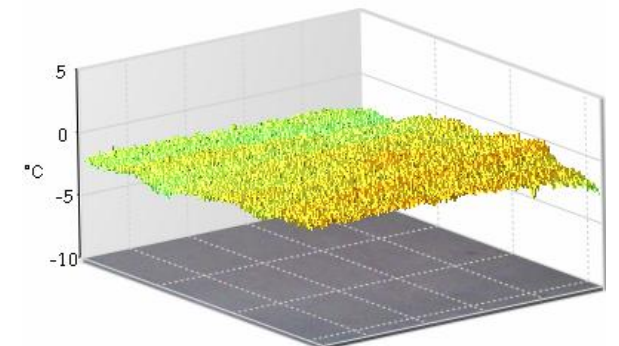

(a) $10 \mathrm{~cm}$

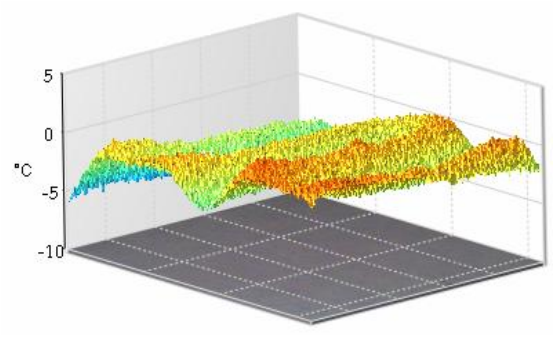

(b) $15 \mathrm{~cm}$

Fig.7 3D-IR Temperture of Pavement for 1 Hour Heating

\section{Summary}

In this paper, the method of melting snow with carbon fiber heating wire (CFHW) buried in concrete pavement is presented to avoid the adverse effects of snow-melting chemicals. It is shown that, with an input power of $500 \mathrm{~W} / \mathrm{m}^{2}$, the average temperature on pavement surface with $10 \mathrm{~cm}$ CFHW spacing is higher than that of $15 \mathrm{~cm}$ CFHW spacing when the air temperature is $-5^{\circ} \mathrm{C}$ and the wind speed is $1.0 \mathrm{~m} / \mathrm{s}$. The pavement heating rates of $10 \mathrm{~cm}$ and $15 \mathrm{~cm}$ CFHW spacing is almost the same in most of the heating time. The temperature different on pavement surface with $10 \mathrm{~cm}$ CFHW spacing is less than $1{ }^{\circ} \mathrm{C}$, which can meet the requirement of the snow-melting temperature uniformity.

\section{Acknowledgement}

This research was financially supported by the National Science Foundation. This work was financially supported by Science and Technology Project of CAAC (MHRD201225), Science and Technology Project of CAAC (MHRD20130109) and Science and Technology Project of CAAC (20150225). 


\section{References}

[1] R.C. Lee, J.T. Sackos, J.E. Nydahl, K.M. Pell, Bridge heating using ground-source heat pipes, Transportation Research Record 962 (1984) 51-56.

[2] X.B. Liu, J.D. Spitler, A simulation tool for the design of the hydronic bridge snow melting system, Proceedings of the 12th International Road Weather Conference, Bingen (on Rhine), Germany, 2004, June 16-18.

[3] X.B. Liu, S.J. Rees, J.D. Spitler, Modeling snow melting on heated pavement surfaces part I: model development, Applied Thermal Engineering, 27 (2006) 1115-1124.

[4] H.N. Xu, Y.Q. Tan, Modeling and operation strategy of pavement snow melting systems utilizing low-temperature heating fluids, Energy, 80 (2015) 666-676.

[5] C.Y. Tuan, S. Yehia, Evaluation of electrically conductive concrete containing carbon products for deicing, ACI Materials Journal 101 (2004) 287-293.

[6] Z.F. Hou, Z.Q. Li, K.J. Guang, The joule heating analysis of electrically conductive concrete for roadway deicing system, Seventh International Symposium on Structural Engineering for Young Exports, Tianjin, China, 2002, pp. 977-1001.

[7] P. Xie, J.J. Beaudoin, Electrically conductive concrete and its application in deicing, Proceedings of the Second CANMET/ACI International Symposium, Las Vegas, USA, 1995, pp. 399-417.

[8] Y. Lai, Y. Liu, D.X. Ma, Automatically melting snow on airport cement concrete pavement with carbon fiber grille, Cold Regions Science and Technology 103 (2014) 57-62.

[9] H.M. Zhao, S.G. Wang, Z.M. Wu, G.J. Che, Concrete slab installed with carbon fiber heating wire for bridge deck deicing, Journal of Transportation Engineering 136 (2010) 500-509.

[10] H.M. Zhao, Z.M. Wu, S.G. Wang, J.J. Zheng, G.J. Che, Concrete pavement deicing with carbon fiber heating wires, Cold regions Science and Technology 65 (2011) 413-420.

[11] H.M. Zhao, Z.M. Wu, , G.J. Che, Interval design of carbon fiber heating wire for pavement deicing, Concrete 245 (2010) 142-144. 